\title{
HLA-B44-Restricted MAGE-3 Peptide
}

National Cancer Institute

\section{Source}

National Cancer Institute. HLA-B44-Restricted MAGE-3 Peptide. NCI Thesaurus. Code C48633.

A peptide comprised of the synthetic human leukocyte antigen (HLA)-B44-binding peptides derived from amino acid sequences of MAGE-3 with potential antitumor activity. Vaccination with HLA-B44-restricted MAGE-3 peptide may elicit a cytotoxic T lymphocyte immune response against tumor cells expressing MAGE-3. MAGE-3 is an antigen found on many tumor cell types, including melanoma and lung, prostate, colon, thyroid, and breast cancers. 